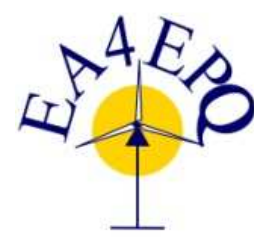

International Conference on Renewable Energies and Power Quality (ICREPQ'13)

Bilbao (Spain), $20^{\text {th }}$ to $22^{\text {th }}$ March, 2013

Renewable Energy and Power Qualiuy. Sournal (RE\&PQJ)

ISSN 2172-038 X, No.11, March 2013

\title{
Improvement of the electric energy quality by use of active power filters
}

\author{
Julian Wosik, Marian Kalus, Artur Kozłowski and Bogdan Miedziński \\ Institute of Innovative Technology EMAG, Katowice, Poland \\ wosik@emag.pl
}

key words: electric power concept, active power filter, load balancing, reactive power, high harmonics

\begin{abstract}
The paper presents basic theories of electrical power used to analyze phenomena in electric circuits with deformed waveforms of current and voltage. Discusses investigated results of application of an active power filter developed on the basis of concept of physical components of the current (CPC).
\end{abstract}

\section{Introduction}

Electric energy is a ware on the market and as a commodity must have a certain quality parameters assured to meet the needs of customers. In the past the basic parameters characterizing the quality of electricity were: continuity of supply, voltage level, voltage frequency.

As commercializing the electric energy appeared a number of other quality indices like:

- impulse disturbances, voltage distortion (notches),

- deformation of the voltage sine wave,

- electromagnetic interference $(10 \mathrm{kHz}-1 \mathrm{GHz}$, $100 \mu \mathrm{V}-300 \mathrm{~V})$,

- voltage sags (up to $0.8 \mathrm{U}_{\mathrm{r}}$, duration less than one period),

- $\quad$ swelling (over $1.1 \mathrm{U}_{\mathrm{r}}$, duration over one period),

- $\quad$ flicker, voltage frequency deviation, outages.

It should be noted that both the supplier and the consumer is responsible for the electricity quality. The most common group of consumers in industry and households create electric motors particularly cage asynchronous. They are usually powered by various frequency convertors to control their speed. For rated power of motors up to about 300-400 kVA uncontrolled convertors (rectifiers) are typically used. However, for higher rated power the controlled are recommended. In both cases we are dealing with nonlinear load what, due to the rapid increase in power convertor applications increases the problem associated with the impact on the power supply network. Flow of the distorted currents causes the deformed voltage drops on respective components of both production, distribution and reception systems. As a result the supplying voltage waveform at basbars of any distribution station is distorted what is critical for users particularly sensitive to the voltage waveform deformation. A side effect of the presence of the power electronics in the power system is an increase of reactive power flows.

For the analysis of the periodical nonsinusoidal quantities the Fourier transform is commonly used.

It presents infinite series of sine waves (harmonics), what for current is as follows:

$$
\mathrm{i}=\mathrm{I}_{\mathrm{m} 1} \cdot \sin \left(\omega_{1} \mathrm{t} \cdot \varphi_{1}\right)+\sum_{\mathrm{n}>1} \mathrm{I}_{\mathrm{mn}} \cdot \sin \left(\mathrm{n} \omega_{1} \mathrm{t}+\varphi_{\mathrm{n}}\right)
$$

where: $\mathrm{n}$ - number of harmonics, $\mathrm{I}_{\mathrm{mn}^{-}}$amplitude of current harmonics, $\omega_{1}-$ angular frequency of basic harmonics, $\varphi_{n}$ - phase of $n$ - harmonics.

Depending on the rectifier structure the harmonics spectrum of current drawn from network can be different. When use for example 6-pulse rectifier it is characterized by odd harmonics of numbers:

$$
\mathrm{n}=6 \mathrm{k} \pm 1 \quad \mathrm{k}=1,2,3,4 \ldots
$$

i.e. $5,7,11,13,17,19,23,25 \ldots$

Therefore to improve the electric energy quality in the system with non-linear loads one has to reduce contents of high harmonics in both voltage and current as much as possible. Among technical solutions used to eliminate high harmonics one of the most attractive seems to be active power filter (APF) application however, its principle of operation and structure must be carefully considered and selected.

Currently for description of phenomena in circuits with deformed voltage and current waveforms are used:

- instantaneous power theory [2],

- theory of the of the current physical components [3].

In the paper the filter developed on concept of physical components of the current (CPC) has been considered and tested. Its efficiency of operation was examined for high power, low voltage non-linear load (mine hoist engine) controlled by power convertor. 


\section{The theoretical basis for construction of active power filters.}

The main task of the active filter application is:

- elimination of high harmonics in current drawn from network,

- reactive power compensation (power factor improvement),

- balancing of asymmetric loads.

Simplified block diagram of the active power filter working in parallel with non-linear load (L) is presented in Fig.1. To ensure stable operation conditions the filter works in an open control system.

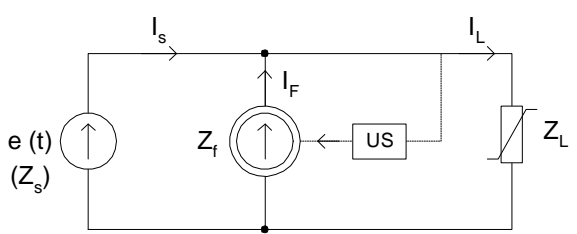

Fig. 1. Block diagram of the active power filter connected in parallel with non-linear power load L; US - control system.

According to Fig. 1. instantaneous load current $i_{s}$ drawn from the voltage source $\mathrm{e}(\mathrm{t})$ of $\mathrm{Z}_{\mathrm{s}}$ impedance is equal to:

$$
i_{S}(t)=i_{L(t)}-i_{F(t)}
$$

where: $i_{L}(t)$ - instantaneous current due to non-linear load (of deformed waveform), $\mathrm{i}_{\mathrm{F}}(\mathrm{t})$ - instantaneous current generated by the active filter.

Therefore, the $\mathrm{i}_{\mathrm{F}}(\mathrm{t})$ has to be appropriately on-line computed and generated to fulfill requirements if about effective operation. So far, mainly the instantaneous power theory has been used in practice for analyzing this problem. It was developed in 1983 by Akagi, Kanazawa and Natae [2] with subsequent modifications to various electrical circuits.

In the paper are presented and discussed the results of the active power filter application developed on the concept of the physical components of current (CPC) [3, 4]. According to the CPC theory in electric circuit with a source of a non-zero impedance $\left(Z_{S}\right)$, that provides energy to a non-linear load, the current and voltage harmonics of the distorted electric quantities can be expressed in the form:

$$
\begin{gathered}
\mathrm{u}=\left[\begin{array}{l}
\mathrm{u}_{\mathrm{a}} \\
\mathrm{u}_{\mathrm{b}} \\
\mathrm{u}_{\mathrm{c}}
\end{array}\right]=\sum_{\mathrm{n} \in \mathrm{N}} \mathrm{u}_{\mathrm{n}}=\sqrt{2} \mathrm{R}_{\mathrm{e}} \sum_{\mathrm{n} \in \mathrm{N}} \underline{U}_{\mathrm{n}} \cdot \mathrm{e}^{\mathrm{jn} \omega_{1} \mathrm{t}} \\
\mathrm{i}=\left[\begin{array}{l}
\mathrm{i}_{\mathrm{a}} \\
\mathrm{i}_{\mathrm{b}} \\
\mathrm{i}_{\mathrm{c}}
\end{array}\right]=\sum_{\mathrm{n} \in \mathrm{N}} \mathrm{i}_{\mathrm{n}}=\sqrt{2} \mathrm{R}_{\mathrm{e}} \sum_{\mathrm{n} \in \mathrm{N}} \underline{I}_{\mathrm{n}} \cdot \mathrm{e}^{\mathrm{jn} \omega_{1} \mathrm{t}}
\end{gathered}
$$

and power $\mathrm{n}$-th harmonics is equal:

$$
\underline{S}_{\mathrm{n}}=\underline{\mathrm{U}}_{\mathrm{n}}^{\mathrm{T}}-\underline{\mathrm{I}}_{\mathrm{n}}^{*}=\mathrm{P}_{\mathrm{n}}+\mathrm{j} \mathrm{Q}_{\mathrm{n}}
$$

where: $\underline{U}^{T}{ }_{n}$ - transposed matrix of voltages, $\underline{I}_{n}^{*}$ - matrix of complex conjugate currents.

For passive linear load the active power for $n$-th harmonics $P_{n}$ is positive $\left(P_{n}>0\right)$ and is provided from the source to the load. If is not fulfilled the respective high harmonics of the current must be generated in the load and the power can therefore, be transferred in the opposite direction $\left(\mathrm{P}_{\mathrm{n}}<0\right)$. Having known the sign of the active power for each harmonics the set of harmonics $\mathrm{N}$ is divided into two subsets $\mathrm{N}_{\mathrm{A}}$ and $\mathrm{N}_{\mathrm{B}}$ respectively (for $\mathrm{P}_{\mathrm{n}}>0, \mathrm{n} \in \mathrm{N}_{\mathrm{A}}$; for $\mathrm{P}_{\mathrm{n}}<0, \mathrm{n} \in \mathrm{N}_{\mathrm{B}}$ ).

$$
\begin{gathered}
i=\sum_{n \in N} i_{n}=\sum_{n \in N_{A}} i_{n}+\sum_{n \in N_{B}} i_{n}=i_{A}+i_{B} \\
u=\sum_{n \in N} u_{n}=\sum_{n \in N_{A}} u_{n}+\sum_{n \in N_{B}} u_{n}=u_{A}-u_{B} \\
P=\sum_{n \in N} P_{n}=\sum_{n \in N_{A}} P_{n}-\sum_{n \in N_{B}} P_{n}=P_{A}-P_{B}
\end{gathered}
$$

If the active power is provided (for $n \in N_{A}$ ) the circuit is considered as a passive one (Fig. 2), similarly the source part for harmonics $n \in \mathrm{N}_{B}$ (Fig. 3).

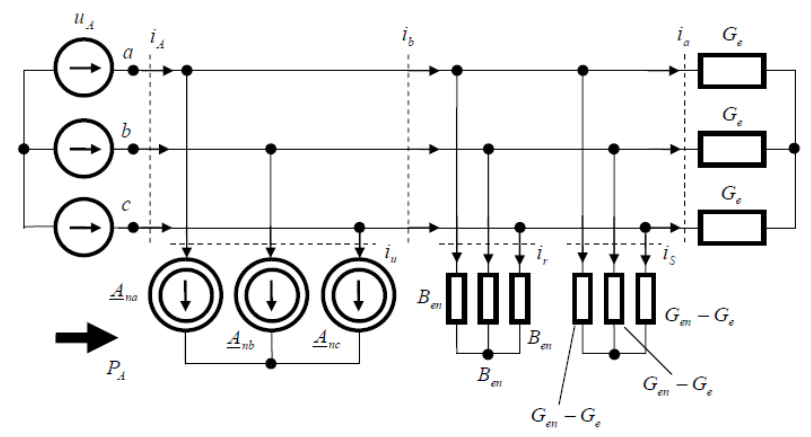

Fig. 2. Substutional circuit for harmonics $n \in N_{A}\left(\right.$ if $\left.P_{n}>0\right)$

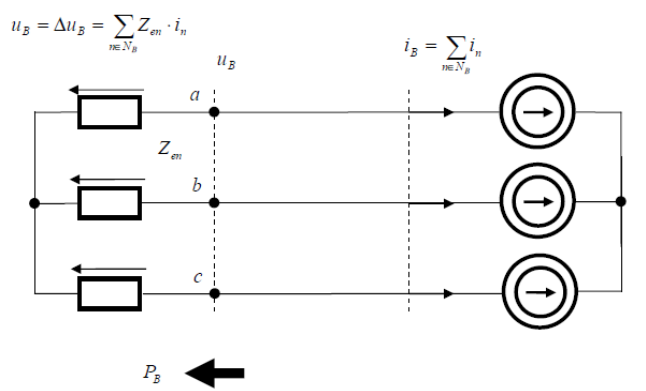

Fig. 3. Substutional circuit for harmonics $n \in N_{B}\left(\right.$ if $\left.P_{n}<0\right)$

According to the CPC theory three-phase unbalanced currents of a non-linear load was decomposed into five components as follows $[3,4]$ :

$$
\mathrm{i}=\mathrm{i}_{\mathrm{a}}+\mathrm{i}_{\mathrm{r}}+\mathrm{i}_{\mathrm{S}}+\mathrm{i}_{\mathrm{U}}+\mathrm{i}_{\mathrm{B}}
$$

where: $i_{a}$ - active current responsible for active power transfer from the source to the load, $\mathrm{i}_{\mathrm{r}}$-reactive current for the load of non-zero susceptance $B_{n} \neq 0$. is - scattered current, if conductance $G_{e n}$ changes with number of harmonics, $i_{U}$ unbalance current for 3-phase systems if the load indicates nonzero imbalance admittance $\left(A_{n} \neq 0\right), i_{B}$ - current of high harmonics due to the non-linear load and related to active power transfer from the load to the source $\left(P_{B}<0, n \in N_{B}\right)$. 
All of these current components are mutually orthogonal.

Algorithm of control power active filter basing on CPC theory is presented in Fig. 4.

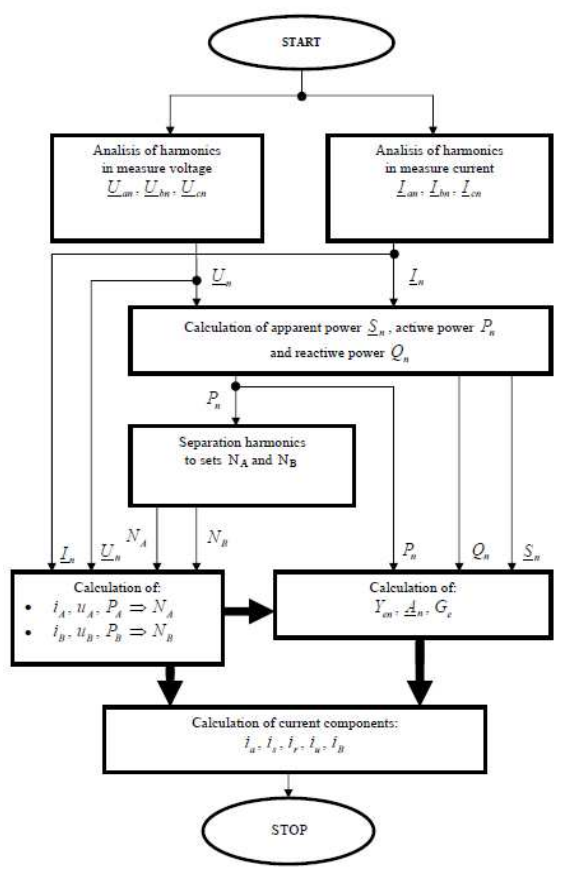

Fig. 4. Algorithm of control Active power filter basing on current physical components theory (CPC)

\section{Investigated results and discussion.}

To verify performance of various systems limiting the negative impact of non-linear loads on the power supply network the appropriate laboratory tests were carried out in circuit as shown in Fig. 5.

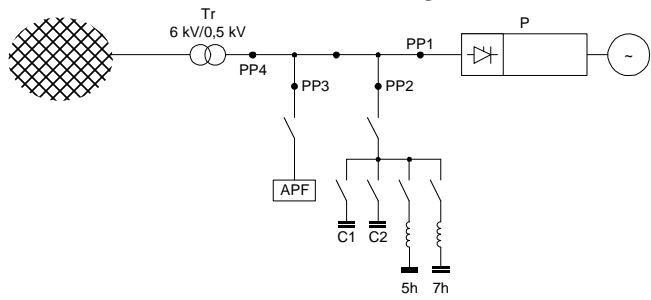

Fig. 5. Schematic diagram of the system for testing; $\mathrm{P}$ - power convertor, APF - active power filter, $5 \mathrm{~h}, 7 \mathrm{~h}$ - passive filters of $5^{\text {th }}$ and $7^{\text {th }}$ harmonics, $\mathrm{C} 1, \mathrm{C} 2$ - compensation capacity banks,PP1-PP4-respective measuring points.

Voltage and current waveforms with a current harmonics spectrum for high power electric motor supplied by uncontrolled rectifier are presented in Fig. 6 . One can see significant deformation of the current drawn from the network at inductive power factor value. Number and value of odd current harmonics is also considerable high. a)

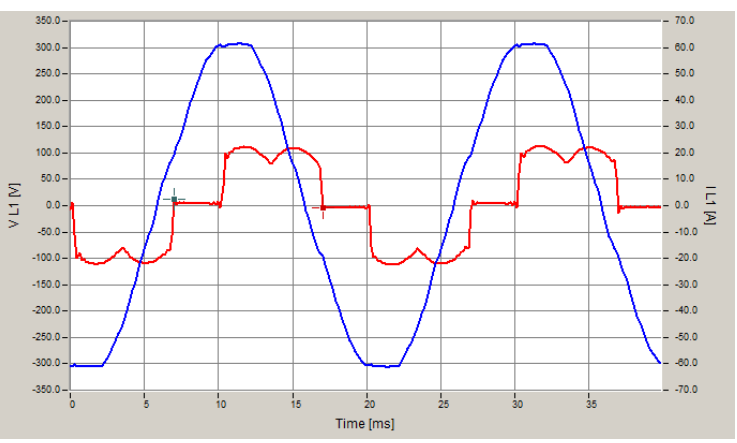

b)

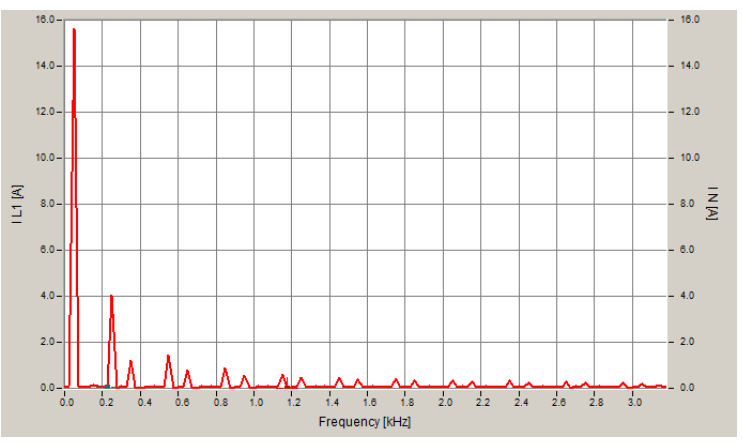

Fig. 6. Voltage (PP4) and current (PP1) due to uncontrolled rectifier (a), current harmonics spectrum (b).

In the case when a controlled rectifier is used (together with capacity bank) the current waveform is much more deformed what is confirmed by the current harmonics spectrum as well (see Fig. 7). However, power factor seems to be improved but deformation of the current flowing through capacitors is increased. Note, that increased contents of the current harmonics is not considered as a good for the capacitors reliability and their time of life as well.

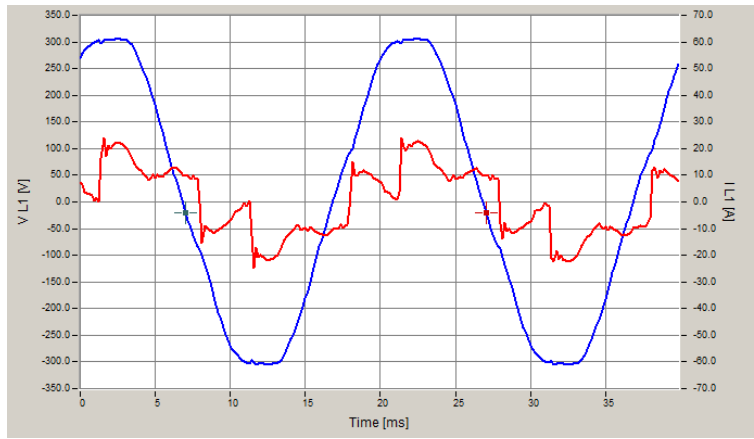

b)

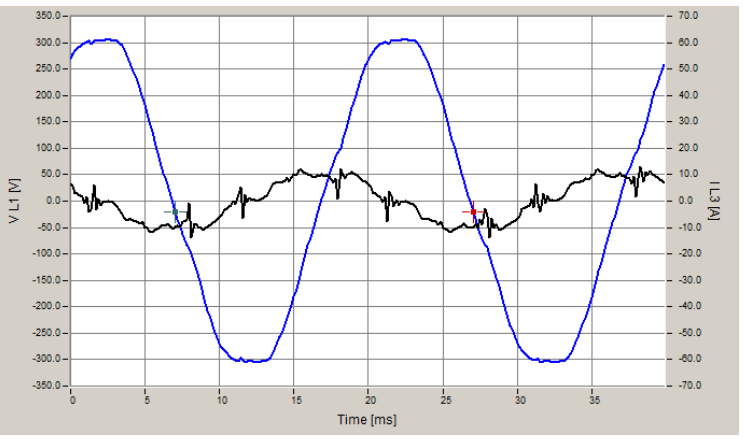


c)

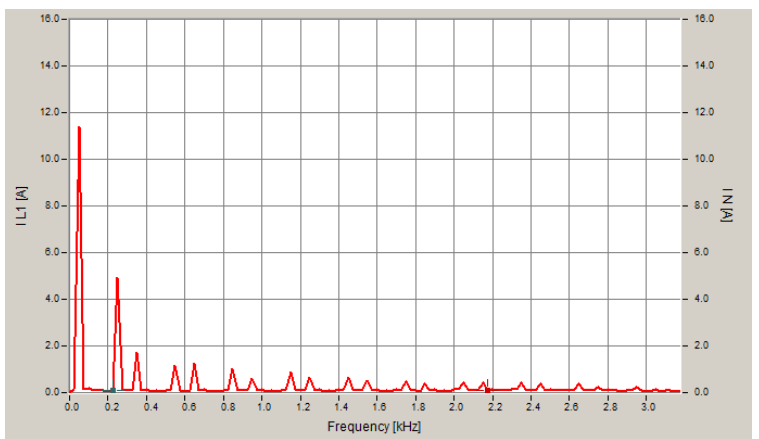

Fig. 7. Voltage (PP4) and current (PP1) waveforms for application of a controlled rectifier $\left(\alpha=50^{\circ}\right)$ together with capacity bank (a); voltage and current at capacity (b); load current harmonics spectrum (c).

Situation is improved somewhat when apply filters of $5^{\text {th }}$ and7th harmonics (see Fig. 8.) however, still it is dangerous case due to increased deformation of the currents waveform flowing through the filters

a)

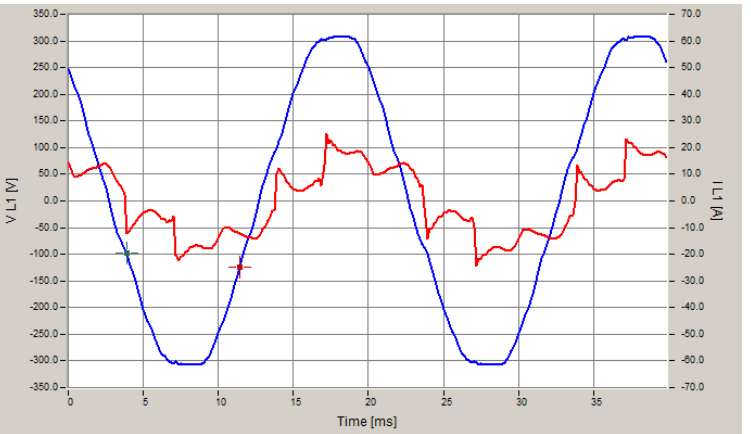

b)
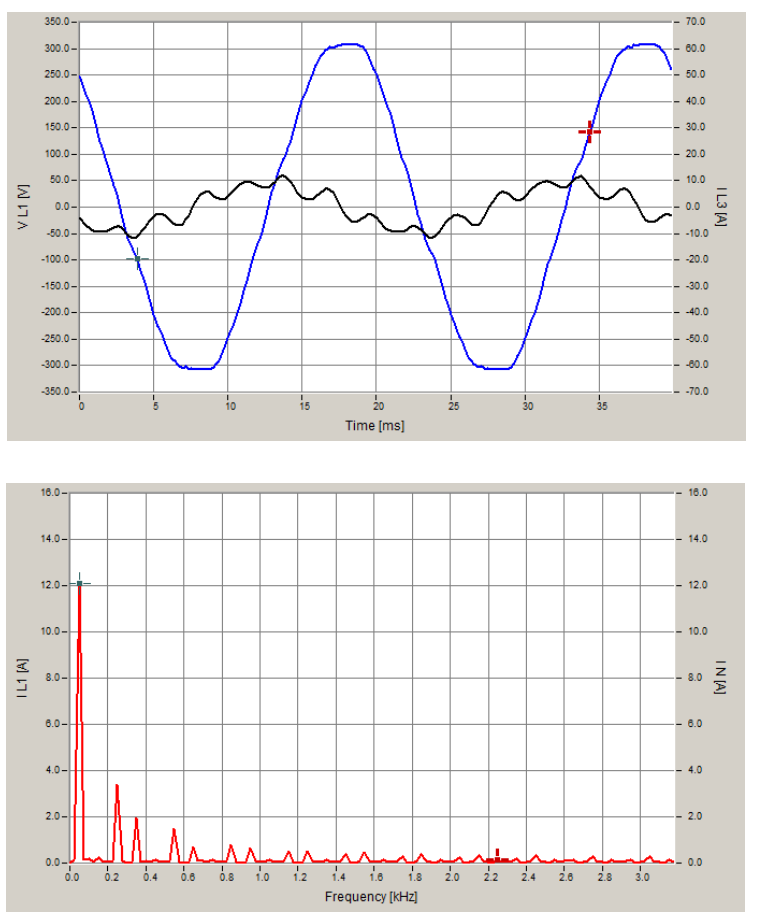

d)

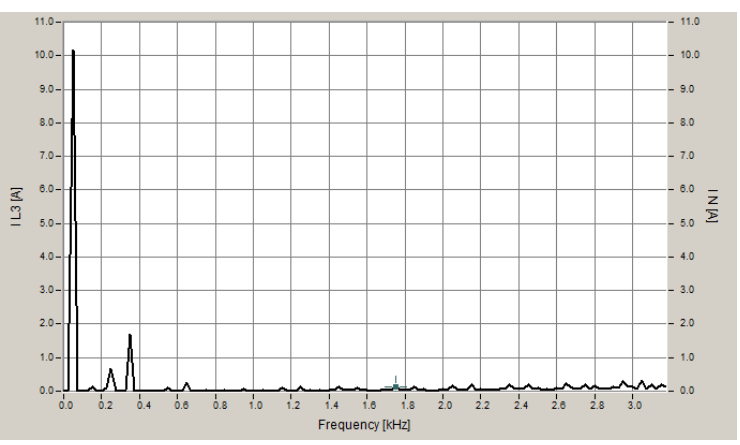

Fig. 8. Voltage (PP4) and current (PP1) waveforms for application of a controlled rectifier $\left(\alpha=50^{0}\right)$ and filters of $5^{\text {th }}$ and $7^{\text {th }}$ harmonics (a); filter current and voltage waveforms (PP2) (b); load current spectrum(d); filter current spectrum (c).

Circuit containing active power filter and shunt capacitor banks can evoke current high harmonics. This problem is illustrated in Fig. 9.

a)..

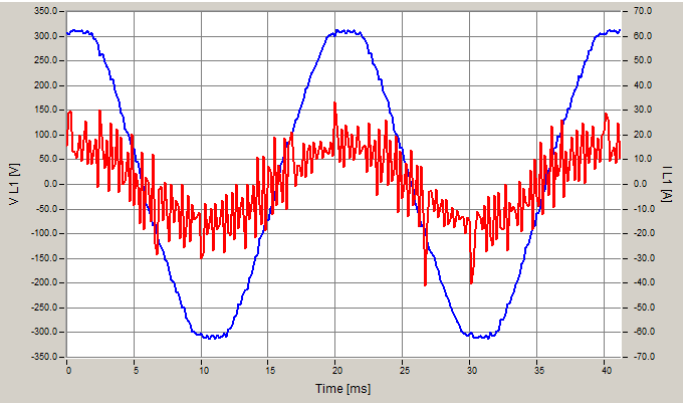

b)

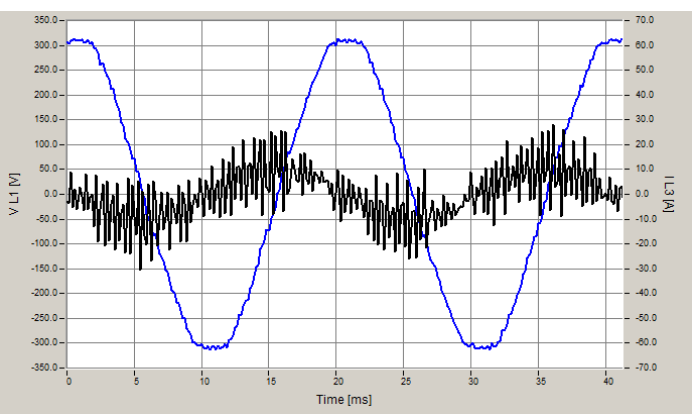

c)

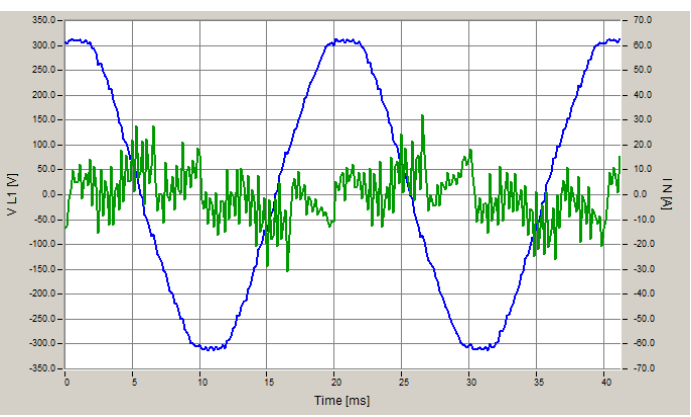


d)

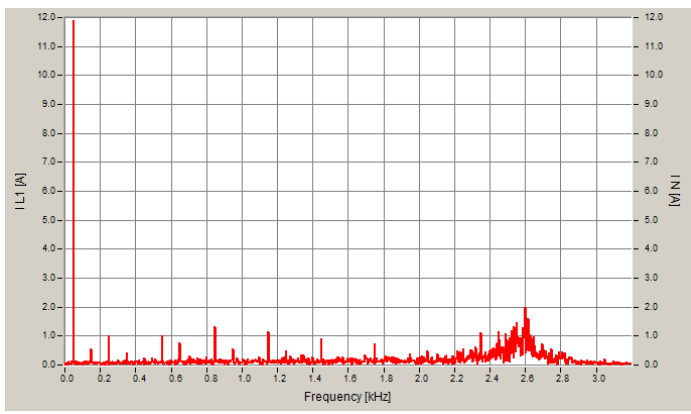

e)

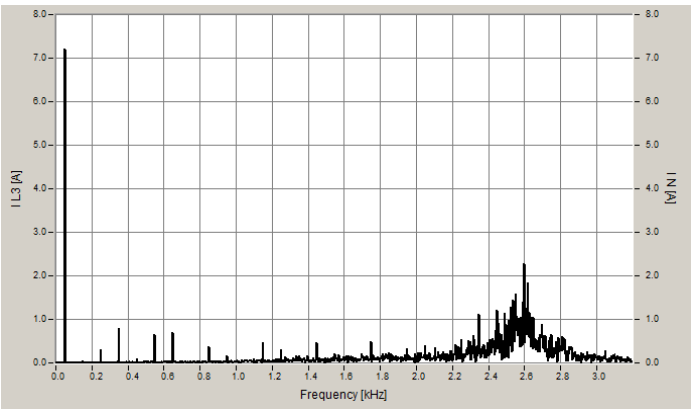

Fig. 9. Voltage and current waveform of source (PPS) - a), voltage and current waveform of capacitor banks (PP2) - b), voltage and current of APF (PP3) - c), spectrum of source current $(\mathrm{PP} 4)-\mathrm{d})$

and spectrum of current capacitor banks (PP2) - e).

Very good results are obtained when use the active power filter. Deformation of both voltage and current waveforms are reduced tremendously what can be compared from the load current spectrum particularly. Phase shift is reduced to zero and load balancing is restored what can be seen when compare results from Fig. 10 and Fig. 11.

a)

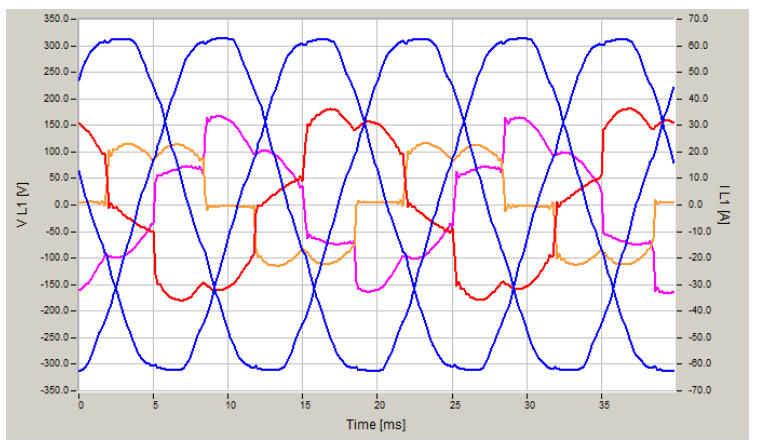

b)

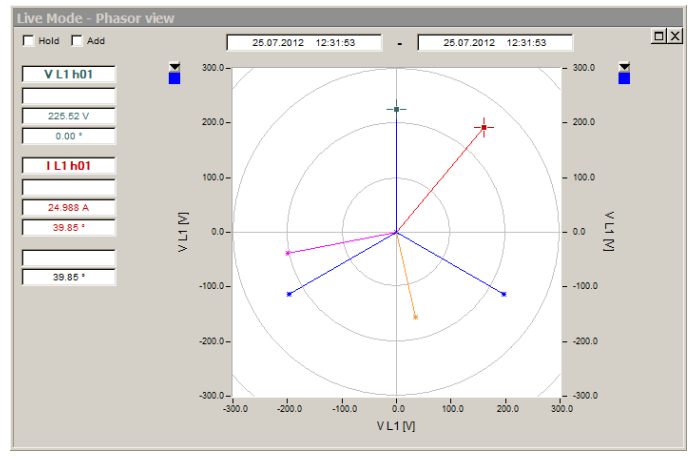

c)

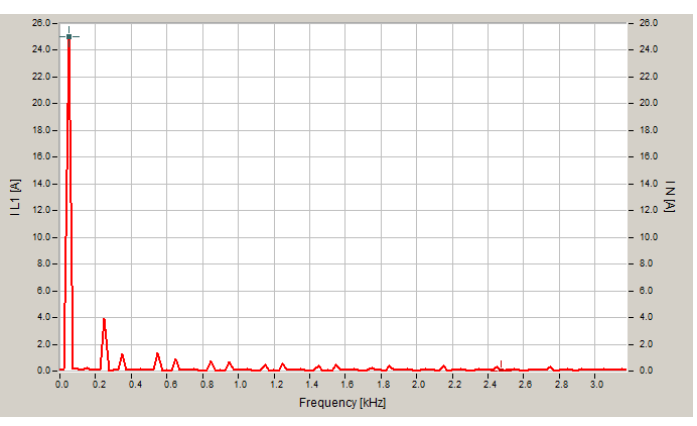

d)

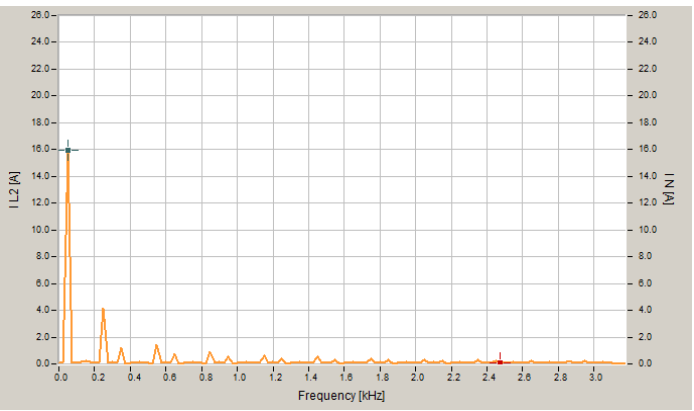

e)

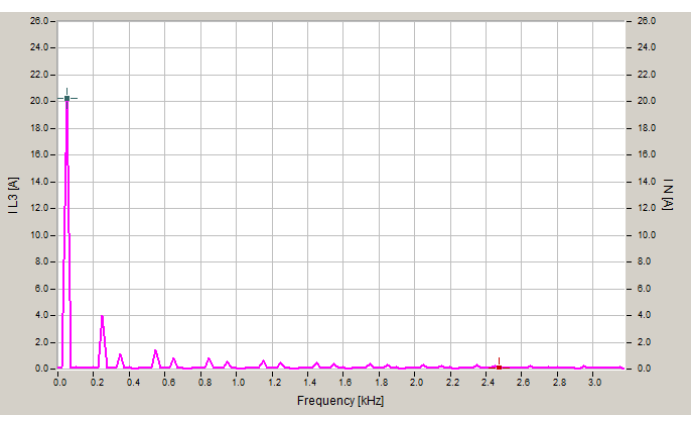

Fig. 10. Current and voltage waveforms (PP4) when use controlled rectifier $\left(\alpha=50^{\circ}\right)$ at involved load asymmetry between L1 and L3 phases (a); voltage and current phases diagram (b), spectrum of current in L1 phase (c), L2 (d), L3 (e).

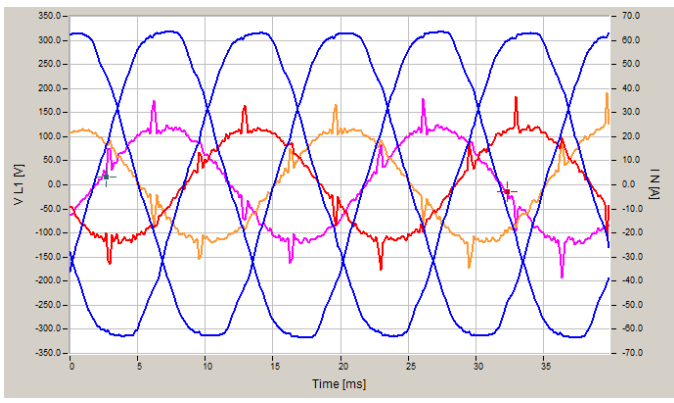

a)

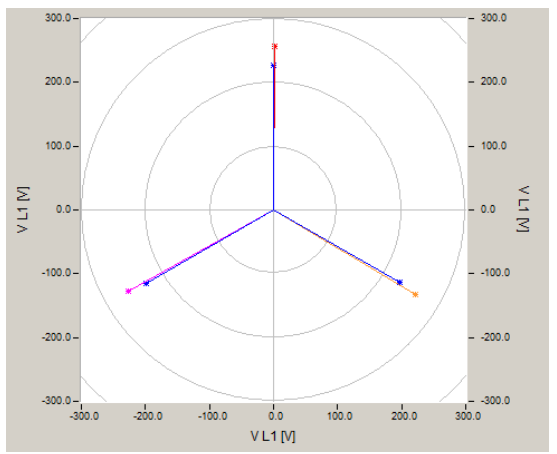


c)

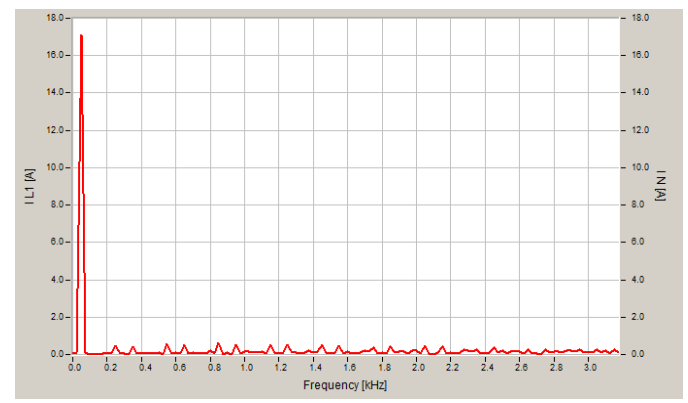

Fig. 11. Current and voltage waveforms (PP4) when use controlled rectifier $\left(\alpha=50^{\circ}\right)$ together with active power filter at involved load asymmetry between L1 and L3 phases(a); voltage and current pharos diagram (b); spectrum of current in L2 phase (c).

\section{Conclusions}

Active power filter developed on basis of the concept of the physical components of current (CPC) indicates high efficiency of operation both if about high harmonics limitation, effective reactive power compensation and balancing of 3-phase asymmetrical load. As a result it can be employed as an effective tool for improving the quality of electricity in distribution networks the more that it can be combined for cooperation together with static filters of selected high harmonics as well as with capacity banks provided it is properly considered and matched.

\section{References}

[1] Bolkowski S.: Theory of electric circuits(in polish) WNT Warszawa 1995

[2] Akagi H., Kanazawa Y., Nabae A.: Generalized theory of the instantaneous reactive power in three phase circuits. Proc. of the Inst. Power Electron. Conf. IIEE IPEC, Tokyo Japan 1983 ,pp1375-1386,

[3] Czarnecki L. S.: An orthogonal decomposition of the current of nonsinusoidal voltage source applied to nonlinear loads. Int. Journal on Circuit Theory and Appl. Vol11,1983 pp235-239,

[4] Czarnecki L. Electric power in circuits with nonsinusoidal waveforms of current and voltage (in polish) Warsaw University of Technology, Warszawa 2005,

[5] Wosik J., Kalus M., Firlit A., Hanzelka Z.: Report on implementation of research project on" Studies on hybrid systems for reactive power compensation"(in polish)unpublished,

[6] Wosik J., Kalus M., Miedziński B.: Analysis of reactive power compensation for nonlinear loads basing on instantaneous power theory. Proc. of XVII Int. Conference SIELA 2012, Bourgas, may 2012 pp. 